Contrast and assimilation effects in judgments

\section{of line configurations containing} the Mueller-Lyer figure*

\author{
LLOYD L. AVANT $†$ \\ Iowa State University, Ames, Iowa 50010
}

Two experiments are reported in which contrast and assimilation effects of anchor line lengths upon focal line lengths were observed. In Experiment 1 straight-line anchors shorter than, and parallel to, focal Mueller-Lyer figures made the figures appear shorter than the same Mueller-Lyers anchored by straight lines longer than the figures. In Experiment 2, focal stimuli were straight lines and parallel anchors were Mueller-Lyer figures. When focal length approximated anchor length, judged length of the focal stimulus was less if anchoring Mueller-Lyers had inward obliques than if the obliques pointed outward. However, as focal length deviated from anchor length, this effect of Mueller-Lyer obliques reversed; outward obliques made focal lines appear shorter than did inward obliques. Results are discussed in terms of adaptation-level theory (A-L theory).

Having reviewed the evidence bearing on seven explanations of the geometrical illusions (three physiological, two informationsampling, and two judgmental theories), Over (1968, p. 599) recently concluded that "the explanation of geometrical illusions now seems no closer than it was 70 years ago." Of the theories Over considered, only the contextual learning theory (Carr, 1935), Ganz's (1966) lateral inhibition theory, and Piaget's (1969) centration theory have not been disaffirmed by available data. However, Over's review makes it clear that each of these three theories is questionable on at least one major issue. For the contextual learning theory there is the difficulty of demonstrating that particular discriminative histories necessarily result in particular error functions in judgment. Ganz's theory fails to account for the influence of experiential and instructional variables on magnitude of illusion and the fact that both contrast and assimilation effects have been observed with some (e.g., the Delboeuf) figures. And, while agreement between observed error functions and predictions from Piaget's (1969) law of relative centrations has been impressive in numerous studies, the centration theory faces difficulty in empirically defining a centration or act of attention.

Of the above three theories, only Piaget's holds all illusions attributable

*Experiment 1 was performed while the author was serving as Visiting Professor at the Behavioral Research Laboratory, U.S. Army Human Engineering Laboratories Aberdeen Proving Ground, Maryland.

tThe author acknowledges, with appreciation, the assistance of Mike Kent and Myron Flemming in collection and analy sis of the data reported here. to similar error-producing processes. In denying the concept of illusion any rightful place in psychology, Boring (1942, pp. 238ff) claimed all illusions accountable by the same perceptual processes-those that govern veridical perception. That illusory perception is inextricable from veridical perception in real-life situations has been amply demonstrated by both Chapanis and Mankin (1967) and Fisher and Lucas (1969).

Consistent with Boring's view is the proposal that perceptual experience may be conceived of as varying along a continuum rnarked, at one extreme, by those perceptions which are determined essentially by the physics of the visual input and, at the other, by those perceptions which are controlled predominantly by intrasubjective variables. Helson's (1964) adaptation-level theory, intended as a general theory of perception, provides a formal model within which an E can work logically unimpeded at any region along this maintains that "perceived spatial properties of objects, such as form, size, distance, and direction, no less than their color qualities, depend upon the pooled effect of the spatial properties of all other objects in the field of view." Considerable evidence in support of this view has recently been reviewed by Avant \& Bevan (1971).

Concerning the geometrical illusions, Helson's specific claim (1964, p. 75) is that "'Mlusions' of length, size, direction, and perspective all attest to the potency of spatial pooling." Green and Stacey (1966), as well as Green and Hoyle (1964a, b), have suggested that A-L theory may be required to account for the illusions, continuum. Helson $(1964$, p. 301) and Restle and his colleagues (e.g., Restle, 1970, 1971; Restle \& Merryman, 1968, 1969) have adapted Helson's quantitative model to account for several size contrast illusions. The Necker cube, no less than the geometrical illusions, reflects the operation of intrasubjective variables, and Turner and Bevan (1964) have shown its perceived orientation to depend upon an orientation norm or adpatation level. And, while their accounts differ considerably in detail, both Restle (1970) and Gilinsky (1971) have offered adaptation level explanations of the moon illusion.

The purpose of this paper is to report two of a series of five experiments in which the anchoring paradigm of A-L theory was adapted for the presentation of focal stimuli and simultaneous contextual anchors or the presentation of anchoring stimuli temporally interspersed among members of the focal stimulus series. The experiments were based on a rationale which considered the illusions to involve perceptual dimensions of varying complexity and required the study of an illusion of linear extent (the simplest dimension), one of areal extent, and one of confluence (the most complex dimension). This report presents the studies of perceived linear extents in stimulus configurations containing the Mueller-Lyer figure.

\section{METHOD}

Subjects

Ten undergraduate females at Iowa State University served as Ss in Experiment 1; 10 males and 10 females served in Experiment 2. All received course credit for research participation. All reported that they had normal vision.

\section{Materials and Procedure}

In Experiment 1, stimulus materials were 12 configurations drawn in India ink on white mimeograph paper (sub. 20) and mounted on sections of Crescent No. 100 posterboard. Each configuration consisted of either the inward- or the outward-oblique half of the Mueller-Lyer figure, drawn horizontally and bordered above and below by a straight horizontal line. The Mueller-Lyer figures were focal stimuli, and the bordering lines were considered anchors. In respective configurations, the main shafts of the Mueller-Lyer figures were 1.5, 2.0, or 2.5 in. long. Each oblique was .167 times the length of its adjacent horizontal shaft, and the angle separating each oblique from the horizontal was $30 \mathrm{deg}$. Bordering lines were either 1.0 or $3.0 \mathrm{in}$. long, and .25 in. separated the horizontal shaft 


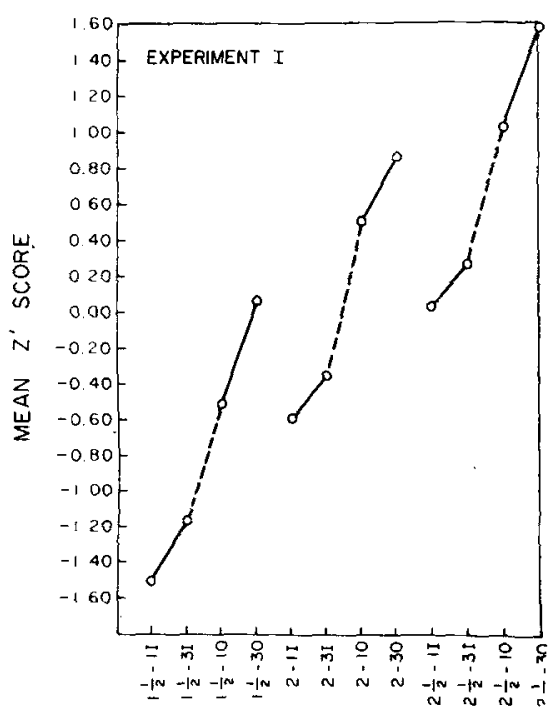

STIMULUS ANCHOR COMBINATIONS

Fig. 1. Average $\mathrm{z}^{\prime}$ scores for each of the 12 illusion-anchor combinations of Experiment 1. Stimulus configurations are identified on the abscissa by: first, focal stimulus length; second, anchor length; and third, inward vs outward obliques on the Mueller-Lyer figure.

of each Mueller-Lyer figure from each of its parallel anchors. Width of all lines was 1/32 in.

The three Mueller-Lyer shaft lengths, two anchor lengths, and inward vs outward obliques of the Mueller-Lyer figure were combined to generate a 12-member stimulus series which was presented for judgment by the method of pair comparisons. Respective pairs of configurations were presented in one of the two $7.75 \times 7.75$ in. fields of a Gerbrands Harvard Tachistoscope, Model T-2B-1; centers of the two configurations in each pair were positioned 1.875 in. to the right and left of a black pinhead dot which marked the center of the viewing field. Left and right placement of each stimulus was equalized across the experiment, and the order in which stimulus pairs were judged was independently randomized for each $S$. Each pair was presented for $.50 \mathrm{sec}$, and for each pair, $S$ was asked to report which of the middle (Mueller-Lyer) lengths appeared longer. As measured by a Spectra Brightness Spot Meter, Model UB1-1/2, maximum lightness of the white field surrounding each stimulus configuration was $12.0 \mathrm{fL}$, while the India ink of the stimulus figures reflected $1.1 \mathrm{fL}$. Between presentations, approximately $10 \mathrm{sec}$ were required for response recording and preparation for the next presentation. During that interval, S viewed the second field of the tachistoscope; that field contained a small centered red fixation cross, and lightness of the field measured $12.0 \mathrm{fL}$ at its center. A ready signal from $E$ cued $S$ to fixate the centered red cross immediately prior to each stimulus exposure. Viewing distance from S's eye to stimulus and fixation fields measured 23.9 in.

After each $\mathbf{S}$ was given instructions, five randomly selected pairs of stimuli were presented as practice trials to precede judgments of all pairs in the test sequence. A 5-min rest period was given each $\mathrm{S}$ half-way through the test sequence. Each S's choice scores, representing judged focal length in respective configurations, were converted to $\mathrm{z}^{\prime}$ scores (Woodworth \& Schlosberg, 1954, pp. 252-254), which were evaluated by analysis of variance.

The rationale of Experiment 2 duplicated that of Experiment 1. Stimulus configurations were drawn as in Experiment 1, but simple straight lines were the focal stimuli and the bordering anchor lengths were Mueller-Lyer figures. Focal lengths were $1-3 / 8,1-5 / 8,1-7 / 8$, or $2-1 / 8$ in., while the horizontal shafts of the Mueller-Lyer anchors were either 1.0 or 2.5 in. As in Experiment 1, the Mueller-Lyer obliques were .167 times the length of the adjacent horizontal and formed a 30-deg angle with the horizontal. These four focal stimulus lengths and two anchoring lengths, combined with the two orientations of the Mueller-Lyer obliques, constituted a 16-member stimulus series for pair comparisons. Apparatus and the procedure for instructions and practice trials, control for right and left placement of each stimulus configuration over trials, and randomization of presentation orders were the same as those employed in Experiment 1. Again, Ss reported the longer of the two focal stimulus lines in each pair, and data were handled as in Experiment 1.

\section{RESULTS}

Average $z^{\prime}$ scores for each configuration employed in Experiment 1 are presented in Fig. 1. As expected, judged focal length increased as length of the Mueller-Lyer figures increased [F(stimulus length $)=156.34, \quad \mathrm{df}=2,18$, $p<.001]$. Direction of the Mueller-Lyer obliques similarly had an expected effect; on the average, inward-oblique figures were judged to be shorter than outward-oblique figures [F(oblique orientation) = 265.63, df $=1,9, p<.0011$. The effect of anchor line length is most clearly seen by considering successive pairs of stimuli from left to right in Fig. 1. The first two stimuli were $1.5 \mathrm{in}$. long and had inward obliques on the Mueller-Lyer figure; the first was anchored by 1-in. lines and the second by 3 -in. lines. In both configurations, the effect of anchor line length paralleled the customary assimilation effect of Mueller-Lyer obliques; apparent length of the main shaft of the Mueller-Lyer figure was less when bordering anchors were 1 in. than when the anchoring lines were 3 in. The same effect is evident in successive pairs of stimuli in Fig. 1. The consistency of this anchor effect was indicated by a highly reliable main effect of anchor length ( $F=17.35$, df $=1,9, p<.001$ ), while none of the interactions were significant. This result suggests that the apparent length of the Mueller-Lyer shaft was determined by the length of that shaft and the functionally identical influences of the distance between tips of the obliques and the length of anchoring lines. The magnitude of the combined influences of intertip distance and anchor length is strikingly illustrated by comparison of $z^{*}$ scores for selected pairs of stimulus configurations. For example, the 1.5-in. outward-oblique figure bordered by 3 -in. anchors appeared almost the same length (mean $z^{\prime}=-1067$ ) as the 2.5-in. inward-oblique figure bordered by 1 -in. anchors (mean $z^{\prime}=: 040$ ).

The results of Experiment 1 were confirmed and extended by the data of Experiment 2. The data from the second experiment are summarized in Fig. 2, which plots the highly significant three-way interaction among stimulus length, anchor length, and anchor obliques $(F=11.26$, $\mathrm{df}=3,54, \mathrm{p}<.001)$. The left panel of Fig. 2 presents average $z^{\prime}$ scores for configurations containing the 1 -in. anchors, and the right panel presents mean $z^{\prime}$ scores for configurations containing the $2.5 \cdot \mathrm{in}$. anchors. The plotted parameter is the influence of anchor obliques across stimulus lengths. The left panel indicates that when the anchors and the focal stimulus were both short ( 1 in. and $1-3 / 8$ in., respectively), the focal stimulus was judged to be shorter when obliques on the Mueller-Lyer pointed inward than when the Mueller-Lyer obliques pointed outward. With the 1 -in. anchors and the longest focal stimulus (2-1/8 in.), the effect of obliques reversed; apparent focal length was less when obliques pointed outward than when they pointed inward. The same effect appears in the right panel of Fig. 2; the focal length which most nearly approximated anchor length was made to appear shorter by inward obliques than by outward obliques, and as focal length deviated from anchor length, this effect of Mueller-Lyer obliques 


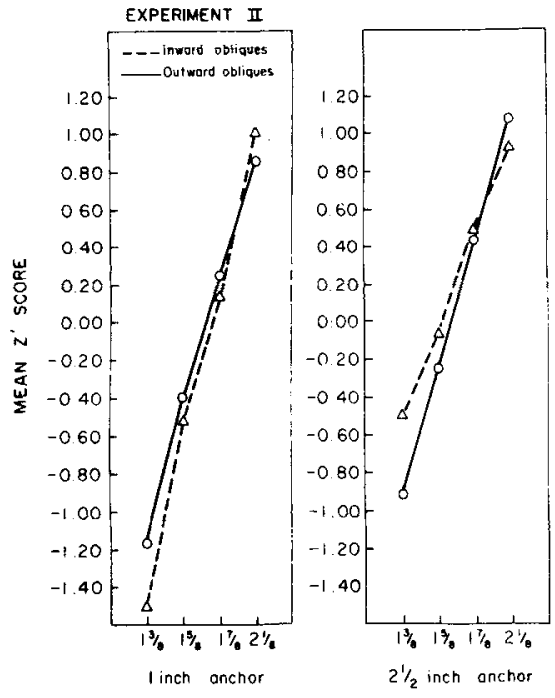

Fig. 2. Average $z^{\prime}$ scores for each of the 16 stimulus configurations of Experiment 2.

was reversed. Thus, both the customary assimilation effect of Mueller-Lyer obliques and the reverse of that effect were observed. Direction of the influence of Mueller-Lyer obliques depended upon the combined influence of all other spatial magnitudes within each array.

\section{DISCUSSION}

Considered in conjunction with data reported earlier by Fellows (1967, 1968), the present findings lend credence to Boring's (1942, p. 245) assertion that "The problem of the geometrical illusions is not a special problem of space perception." They are likewise consistent with Helson's $(1964,1971)$ claim that contrast and assimilation are not antithetical phenomena, but are, instead, extremes of a continuum of perceptual effects.

Fellows (1967) varied the length of horizontal lines placed in the open gap between Mueller-Lyer obliques from $1 / 8$ to $7 / 8$ of the extent of the gap. As enclosed line length increased from $1 / 8$ to $1 / 2$ of the gap, a reversed effect of Mueller-Lyer obliques increased in magnitude. Lengthening the enclosed line to $3 / 4$ or $7 / 8$ of the gap shifted the effect of obliques to the customarily observed assimilation effect. In a further study, Fellows (1968) took the important additional step of duplicating these findings when test lines were enclosed within a rectangle whose horizontal and vertical dimensions matched those of the previous Mueller-Lyer obliques. Compared to unenclosed lines, enclosed lengths revealed the same contrast and assimilation effects of the enclosing rectangle that had been observed previously with the Mueller-Lyer obliques. Thus, the contrast and assimilation effects observed by Fellows were not peculiar to the "illusory" Mueller-Lyer obliques; they likewise appeared when line length was judged in the "nonillusory" context of a rectangle. The continuum of effects observed by Fellows requires, for its explanation, a theoretical account incorporating veridical and illusory perception, even if the enclosing rectangle he employed is considered a contrast illusion, as is suggested by Over (1968, p. 546). Fellows's results are comparable to the present findings that perception of the Mueller-Lyer figure is systematically influenced by "nonillusory" straight lines and that contextual Mueller-Lyer figures prompt the full range of effects from contrast to assimilation in the perception of focal straight lines.

The contrast and assimilation effects reported here are also notably similar to the range of effects observed by Helson and his colleagues in studies of perceived lightness (Helson, 1963; Helson \& Joy, 1962; Helson \& Rohles, 1959) and in studies of weight judgment (Heison \& Nash, 1960). In the studies of lightness perception, the investigators varied the width and reflectance value of gray background strips which alternated with black or white stimulus lines of varying widths. The outcome of these studies is illustrated in the report by Helson and Joy (1962), that with lines of 3- to approximately $8 \cdot \mathrm{mm}$ widths, intervening medium gray areas of 3- to $50-\mathrm{mm}$ widths appeared lighter as background for white lines and darker as background for black lines. As line width was increased beyond $10 \mathrm{~mm}$ to $50 \mathrm{~mm}$, the gray background between black lines was judged lighter and that between white lines was judged darker. The division between contrast and assimilation effects occurred when line width was $10 \mathrm{~mm}$. Helson (1963) has advanced a physiological hypothesis, based on the differences in stimulation of neighboring retinal areas, which synthesizes both contrast and assimilation effects in lightness perception within adaptation-level theory, and the hypothesis has obtained experimental support in tests by Steger (1969).

In their study of weight perception, Helson and Nash (1962) reported effects of anchor weights which are analogous to those observed in the present studies of the Mueller-Lyer figure and those observed in the studies of lightness perception. Helson and Nash asked Ss to judge members of overlapping series of weights, first with no interpolated anchor weight and then with anchor weights well removed from either extreme of the range of series weights. Differences in judgments of the anchored and unanchored series revealed that in each of the separate but overlapping series, the anchor weights exerted greater repellent effects on series stimuli nearer the anchoring value than on series members farther removed. However, the effect of anchors on each series taken as a whole was opposite the contrast effect upon individual members of each series; repellent effect of the anchors was greater for series farther removed from the anchoring value and less for the series nearer the anchoring value.

The present data lack the specifics of a physiological hypothesis to account for all observations. For example, it is not entirely clear why and how the unfilled linear extent between tips of the Mueller-Lyer obliques seems to be processed in the same manner as are well-defined lines. However, several considerations recommend an adaptation-level interpretation of the data.

First, Helson's formulation requires no distinctions in perceptual processing peculiar to illusory, as opposed to veridical, perception. For the focal stimuli of the present studies, a conceptual separation was made between stimuli which are usually veridically perceived (straight lines) and those which are illusory (Mueller-Lyer figures); a similar distinction was made for the contextual anchors. Thus, in Experiment 1, the focal stimuli were illusory and contextual anchors were nonillusory, while in Experiment 2, focal stimuli were nonillusory and anchors were illusions. It is to be noted that in these studies, no configurations containing straight focal lines without either anchors or Mueller-Lyer obliques were employed. Thus, it is not possible to state, for example in Experiment 1, exactly what average $z^{\prime}$ stores would have been obtained for straight focal lines measuring $1.5,2.0$, or 2.5 in. and serving as control configurations without either Mueller-Lyer obliques or anchoring lines. The present data, as well as the findings of other investigators (e.g., Kunnapas, 1955; Restle, 1971), make it clear, however, that perceived linear magnitudes are systematically influenced by the spatio-temporal parameters of their context. Künnapas (1955) demonstrated that judged length of simple straight lines varied inversely with the size of the open field in which they were centered. Similarly, Restle (1971) found, in studies involving the Baldwin size contrast illusion, that the control function served by straight lines presented in an otherwise empty field was severely 
compromised by the influence of the temporally dispersed context provided in other series stimuli. Judged lengths of Restle's control lines were quite variable and unstable across experimental conditions. The present data indicate that perceived length, whether main shaft of the Mueller-Lyer figure, distance between tips of the Mueller-Lyer obliques, or simple straight lines, results from the pooled influence of all linear magnitudes relevant to the length singled out for judgment. Experimental designation of some lengths as controls and others as series stimuli apparently exempts neither stimulus classification from the pooled influence of the parameters of all relevant stimuli in the spatio-temporally dispersed context. The finding, in Experiment 1, that apparent length of focal Mueller-Lyer figures was assimilated to the length of parallel "nonillusory" anchor lines makes it reasonable to infer that when the Mueller-Lyer figure is viewed alone, apparent length of the main shaft is assimilated to the length of the open gap between tips of the obliques by the pooling of the three linear extents.

The observation, in Experiment 2, that obliques on the Mueller-Lyer anchors prompted the full range from contrast to assimilation effects is also compatible with adaptation-level theory. Piaget's (1969) theory also outlines the way a single perceptual mechanism operates to produce veridical perception with some spatial arrangements but errors with others. However, Piaget's theory maintains all illusions to be of the contrast form; when spatial arrangements involve size inequalities, more acts of attention are initially directed to the larger contours, accentuating any size differences. This accentuation of differences may be offset by continued perceptual activity which more evenly samples information.
However, the method employed in the present studies (pair comparisons with .50 -sec stimulus exposures) would be expected to limit perceptual activities to initial accentuation of size differences and, according to Piaget's theory, result in only contrast effects of anchors.

Finally, adaptation-level theory clearly implies a commonness of perceptual processing along various perceptual dimensions, and the present findings are directly analogous to adaptation-level phenomena observed in earlier studies of lightness and weight perception.

\section{REFERENCES}

AVANT, L. L., \& BEVAN, W. Adaptation level and visual space perception. In M. H. Appley (Ed.), Adaptation level theory (symposium). New York: Academic Press, 1971, in press.

BORING, E. G. Sensation and perception in the history of experimental psychology. $\mathrm{New}$ York: Appleton-Century-Crofts, 1942

CARR, H. A. An introduction to space perception. New York: Longmans, Green, 1935.

CHAPANIS, A., \& MANKIN, D. A. The vertical-horizontal illusion in a visually rich environment. Perception \& Psychophy sics, 1967, 2, 249-255.

FELLOWS, B. G. Reversal of the Müller-Lyer illusion with changes in the length of the inter-fins line. Quarterly Journal of Experimental Psychology, $1967,19,208-214$

FELLOWS, B. G. The reverse Müller-Lyer illusion and "enclosure." British Journal of Psychology, 1968, 59, 369-372.

FISHER, G. H., \& LUCAS, A. Illusions in concrete situations: I. Introduction and demonstrations. Ergonomics, 1969, 12, 11-24.

GANZ, L. Mechanism of the figural aftereffects. Psychological Review, 1966, 73, 128-150.

GILINSKY, A. S. Adaptation level contrast, and the moon illusion. In $M . H$. Appley (Ed.), Adaptation level theory (symposium). New York: Açademic Press, 1971, in press.

GREEN, R. T., \& HOYLE, E. M Adaptation-level and the optico-geometric illusions. Nature, 1964a, 201, 1200-1201.

GREEN, R. T.» \& HOYLE, E. M. The influence of spatial orientation on the Poggendorff illusion. Acta Psychologica, $1964 b, 22,348-366$

GREEN, R. T., \& STACEY, B. G. Misapplication of the misapplied constancy hypothesis. Life Sciences, $1966,5,1871-1880$.

HELSON, H. Studies of anomalous contrast and assimilation. Journal of the Optical Society of America, 1963, 53, 179-184.

HELSON, H. Adaptation-level theory. New York: Harper \& Row, 1964.

HELSON, H. Adaptation-level theory 1970-and after. In M. H. Appley (Ed.), Adaptation level theory (symposium). New York: Academic Press, 1971, in press.

HELSON, H. \& JOY, V. Domains of lightness assimilation and contrast effects in visian. Psychologische Beiträge, 1962, $6,405-415$.

HELSON, H., \& NASH, M. C. Anchor, contrast, and paradoxical distance effects. Journal of Experimental Psychology, $1960,59,113-121$.

HELSON, H. \& ROHLES, F, H., JR, A quantitative study of reversal of classical lightness contrast. American Journal of Psychology, 1959, 72, 530-538.

KÜNNAPAS, T. M. Influence of frame size on apparent length of a line. Journal of Experimental Psychology, 1955, 50, $168 \cdot 170$.

OVER, R. Explanations of geometrical illusions. Psychological Bulletin, 1968, 70, 545-562.

PIAGET, J. The mechanisms of perception. (Translated by G. N. Seagrim.) New York: Basic Books, 1969.

RESTLE, F. Moon illusion explained on the basis of relative size. Science, 1970,167 1092-1096.

RESTLE, F. Visual illusions. In $M$. $H$. Appley (Ed.), Adaptation level theory (symposium). New York: Academic Press, 1971, in press.

RESTLE, F., \& MERRYMAN, C. T. An adaptation-level theory account of a relative size illusion. Psychonomic Science, 1968, 12, 229-230.

RESTLE F \& MERRYMAN, C. Distance and an illusion of length of line. Journal of Experimental Psychology, 1969, 81, 297-302.

STEGER, J. A. Visual lightness assimilation and contrast as a function of differential stimulation. American Journal of Psychology, 1969, 82, 56-71.

TURNER, E. D.. \& BEVAN, W. Patterns of experience and the perceived orientation of the Necker cube. Journal of General Psychology, 1964, 70, 345-352.

WOODWORTH, R. S \& SCHLOSBERG, H Experimental psychology. (Rev, ed.) New Yotk: Henry Holt, 1954.

(Received for publication June 3, 1971.) 